\title{
Luminescence dating of reticulated red clay buried in Lanshanmiao Paleolithic site in Zhejiang Province, southern China
}

\author{
LU Ying ${ }^{1}$, "SUN Xuefeng ${ }^{1}$, XU Xinmin", LIU Yalin², YI Shuangwen ${ }^{1}$ \\ 1. School of Geography and Ocean Science, Nanjing University, Nanjing 210023, China; \\ 2. Zhejiang Provincial Institute of Cultural Relics and Archaeology, Hangzhou 310014, China
}

\begin{abstract}
The Lanshanmiao (LSM) Palaeolithic site, which was excavated in the summer of 2017 by the Zhejiang Provincial Institute of Cultural Relics and Archaeology, is the only excavated palaeolithic site in central Zhejiang Province to date. Luminescence dating methods, including optical stimulated luminescence (OSL) and thermal transfer OSL (TT-OSL) for quartz and post-infrared (IR) stimulated luminescence (pIRIR ${ }_{290}$ ) for feldspar, were used to determine the age of the LSM site. The results showed that the LSM section developed before $145.5 \pm 12.5 \mathrm{ka}$ and ended after $17.1 \pm 1.0 \mathrm{ka}$. The TT-OSL dating of samples NJU2576 and NJU2615 showed that palaeolithic artifact-bearing layer was between 150 and $100 \mathrm{ka}$ in age. The age range of the palaeolithic layer mainly corresponded to the transition between Marine Isotope Stage (MIS) 6 and MIS5. Our study showed that hominins prominently occupied the LSM site during the glacial and interglacial stages, when it exhibited a floodplain environment.
\end{abstract}

Keywords: Lanshanmiao site; Palaeolithic; reticulated red clay; luminescence dating; glacial; interglacial

\section{Introduction}

Over 2000 palaeolithic sites, most of which were buried in loess deposits, have been discovered in China (Gao, 2019). Loess deposits in China are divided into typical loess, which occurs on the Loess Plateau of Central China, and atypical loess, which occurs in other areas, such in the Qinling Mountain Range, in the Xiashu loess, and in Quaternary reticulated red clay in the lower drainage of the Yangtze River (Liu et al., 1985; Xiong et al., 2000; Sun et al., 2017a; Wang et al., 2008). Accurate age estimates are available for most palaeolithic sites in the loess regions in North and Central China (e.g., Chen et al., 1984; An et al., 1990; Xiao et al., 2002; Yang et al., 2005; Nian et al., 2014b; Wang et al., 2005, 2008, 2014, 2016; Nian et al., 2016; Lu et al., 2007, 2011a, 2011b; Sun et al., 2012, 2013, 2014, 2016, 2017b, 2018; Lu et al., 2017; Wang et al., 2019). However, dating information is lacking for sites

Received: 2020-03-06 Accepted: 2020-06-02

Foundation: National Natural Science Foundation of China, No.41972185, No.41690111

Author: Lu Ying, PhD Candidate, specialized in physical geography. E-mail:mg1927013@smail.nju.edu.cn

"Corresponding author: Sun Xuefeng, PhD and Associate Professor, E-mail: xuefeng@nju.edu.cn 
buried in reticulated red clay.

As excavation in the lower reaches of the Yangtze River has expanded, palaeolithic sites buried in Quaternary reticulated red clay have been increasingly unearthed; these discoveries aid the study of the evolution of palaeolithic culture in this area. Quaternary reticulated red clay is widely distributed in the lower reaches of the Yangtze River and is sensitive to the East Asian monsoon (Huang et al., 1999; Qiao et al., 2003; Yin and Guo, 2006; Yuan et al., 2008). These conditions are significant for understanding the linkage between hominin activity and climatic change in South China (Hu et al., 1999; Zhu et al., 2005, 2011; Xu, 2008). However, reticulated red clay is also generally affected by weathering, which causes the preservation of bones or organic matter for radiocarbon and uranium-series dating to be less likely. The main methods previously used to date reticulated red clay have involved palaeomagnetic and stratigraphic correlations (Yuan et al., 2008; Liu and Deng, 2011; Deng et al., 2019); however, these techniques cannot provide a high-resolution chronology, except ages that occur during polarity reversals.

Earlier studies provided an ambiguous chronological framework for the Quaternary reticulated red clay in the middle-lower drainage of the Yangtze River, suggesting that the clay mainly developed during the Middle Pleistocene. The lower boundary age of the reticulated red clay is 1-1.2 Ma, as estimated by palaeomagnetic and stratigraphic correlations (Liu et al., 2008; Deng, 2019). No consensus has been reached for the top boundary age of the reticulated red clay. Climatic stratigraphy and pedological analysis have shown that the upper limit of the reticulated clay is 400-500 ka and is characterized by an extremely warm and humid environment (Qiao et al., 2003; Yin et al., 2006; Deng et al., 2019). In other cases, dating methods such as luminescence dating was used to date the reticulated red clay to the Early-Late Pleistocene (Mao et al., 2008; Han et al., 2012). These age estimates provide references for palaeolithic sites found in the reticulated red clay. However, most sites lack independent and credible age estimates. Further chronological studies on the reticulated red clay are essential, especially those based on excavations of palaeolithic sites, and will contribute to the construction of palaeolithic cultural sequences and corresponding climatic stages.

Luminescence dating is a robust Quaternary dating method and has been widely used in dating Chinese palaeolithic archaeological sites (e.g., Zhang et al., 2019, 2010; Sun et al., 2010, 2012, 2013; Nian et al., 2014a; Nian et al., 2016; Guo et al., 2016, 2017; Hu et al., 2019, Huang et al., 2019). It has been applied to reticulated red clay deposits and used to obtain reliable chronological results (e.g., Han et al., 2012; Zhang et al., 2007, 2019; Huang et al., 2019). Problems caused by deposit weathering may influence the application of luminescence dating and lead to instability in the dose rate and the extraction of feldspar (Lai et al., 2001; Zhang et al., 2007; Yi et al., 2018). Nevertheless, luminescence dating results have been proven to be credible when the fluctuation in the dose rate is within the limits of experimental error (Zhang et al., 2019), while feldspar extracted from weathered deposits for luminescence measurements may generate reasonable age estimates (Huang et al., 2019). In this study, we attempted to use luminescence dating methods to date the Lanshanmiao (LSM) site, which is located in a reticulated red clay area, to further interpret its archaeological and environmental implications. 


\section{Geographic, stratigraphic, and archaeological investigations}

The LSM Palaeolithic site is located in the west Shengzhou Basin, $3.5 \mathrm{~km}$ southwest of the Chongren County $\left(120^{\circ} 41^{\prime} 37^{\prime \prime} \mathrm{E}, 2^{\circ} 34^{\prime} 37^{\prime \prime} \mathrm{N}\right.$; Figure 1) at an elevation of $45 \mathrm{~m}$. The Chongren River lies approximately $1.5 \mathrm{~km}$ east of the LSM site; this river is a tributary of the upper reaches of the Cao'e River. At present, more than 80 palaeolithic sites have been found in Zhejiang Province (Zhang, 2003; Xu, 2008; Guo et al., 2016). Most of these palaeolithic sites are concentrated in the Xitiaoxi River Basin or Taihu Lake Basin. Furthermore, two sites containing human fossils, including those of the Tonglu Man and Jiande Man, were found in the Qiantang River Basin (Xu, 2008). To date, LSM is the only excavated palaeolithic site in the Cao'e River Basin (Figure 1). The modern climate in this area is that of a subtropical monsoon region, with a mean monthly temperature of $4.2^{\circ} \mathrm{C}$ in January and $28.6^{\circ} \mathrm{C}$ in July and an average annual precipitation of $1446.8 \mathrm{~mm}$.

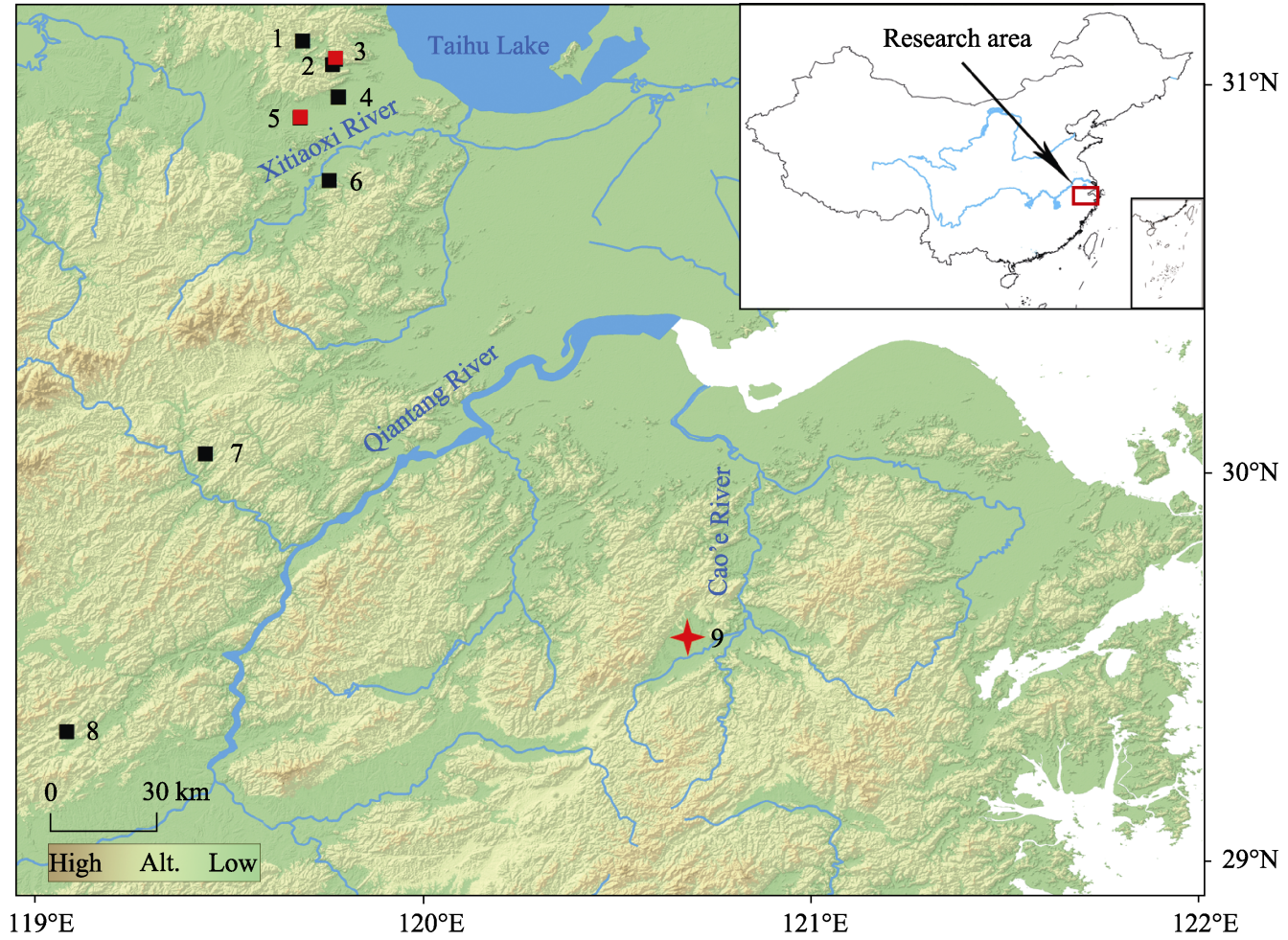

Figure 1 Locations of the LSM (9), Qiliting (QLT) (5), and Yindinggang (YDG) (3) sites and other areas in the Zhejiang Province, including 1-Zijinshan, 2-Hexi Cave No. 1, 4-Wangjiashan, 6-Shangmakan, 7-Tonglu Man, and 8-Jiande Man

The field excavation was conducted by the Zhejiang Provincial Institute of Cultural Relics and Archaeology in the summer of 2017 (Figure 2a). The disturbed topsoil was cleared and a deposit from the LSM section (4.65 m thickness) was collected. The first natural soil layer was labeled Layer 1 and the bottom layer was labeled Layer 5 (Figure 2b). The degree of reticulation gradually increased from Layer 2 to Layer 5. Layer 5 (below $4 \mathrm{~m}$ ) comprised strong reticulated red clay. The top layer measured $0-1 \mathrm{~m}$ in depth and was composed of 
brown (7.5YR 4/6) loose silty clay with numerous small spherical Fe-Mn oxide nodules. Layers $2(1-1.75 \mathrm{~m})$ and $3(1.75-2.75 \mathrm{~m})$ consisted of weakly reticulated brown clay (7.5YR $5 / 6)$. Layer 3 was marked by hard clay and an evident loose gray (10YR 8/2) reticulated pattern. Layer $4(2.75-4 \mathrm{~m})$ was dominated by reticulated red (10R 4/8) clay with a hard texture.
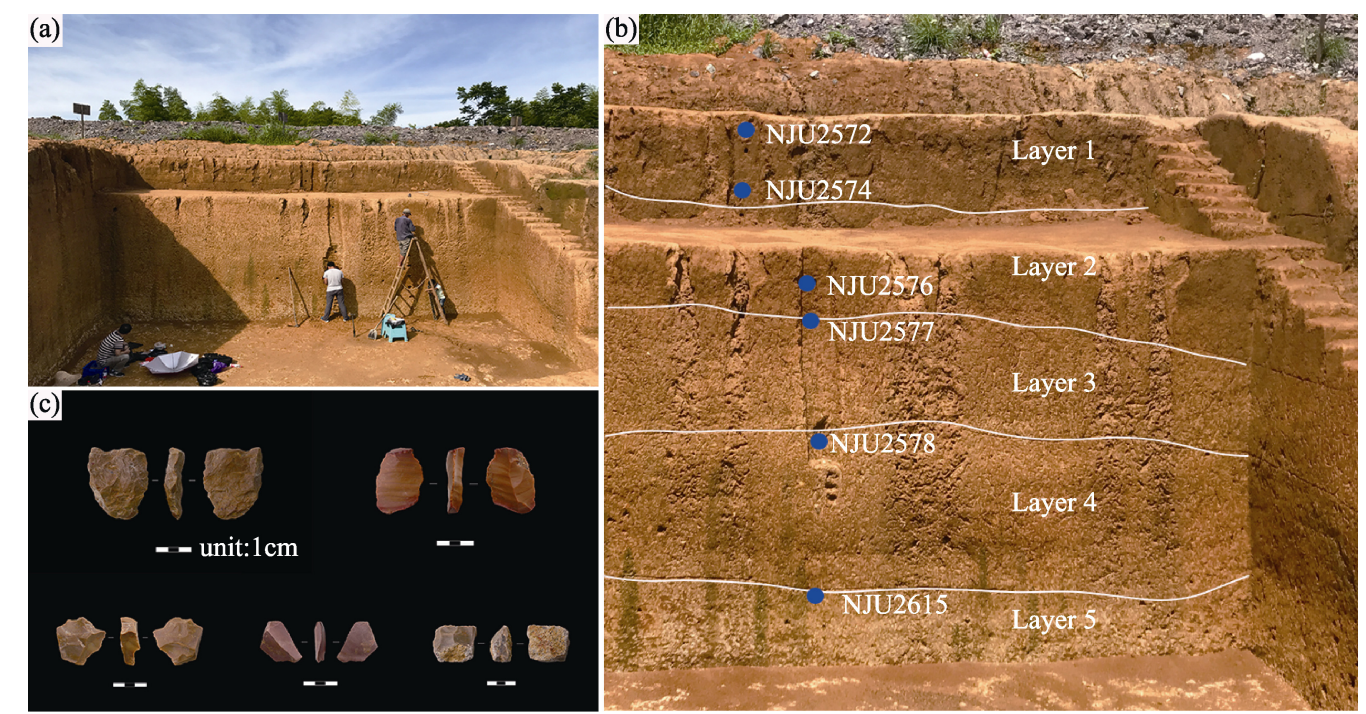

Figure 2 Fieldwork at the LSM site and the stone artifacts uncovered (a. Scenery at the LSM Palaeolithic site; b. LSM stratigraphy with blue points indicating the sampling positions; c. palaeolithic artifacts)

More than 60 palaeolithic artifacts were unearthed from a $60 \mathrm{~m}^{2}$ trench. The relics mostly included broken pieces, with several flakes and cores (Figure 2c). The stone artifacts were scattered from Layer 2 to Layer 5 in the reticulated red clay. These artifacts were dominated by flint and quartzite material. Among these artifacts of stone, the small stone fragments and stone cores mostly comprised quartzite and red-purple high-quality flint, and were modified by simple hammering and stripping methods. Numerous small pebbles and breccia coexisted in Layer 3 to Layer 5.

\section{Luminescence dating}

\subsection{Sampling, laboratory measurement, and protocols}

We inserted a metal tube in the cleaned loess section and obtained six samples at the LSM site for luminescence dating (Figure 2b). The samples were sealed with tape and preserved in black plastic bags to avoid exposure and water loss by dispersion. Four samples were collected in the cultural layer below $1 \mathrm{~m}$. NJU2572 and NJU2574 were sampled 0.1 and 0.75 $\mathrm{m}$ above the cultural layer, respectively. NJU2578 and NJU2615 were sampled at depths of 2.75 and $4 \mathrm{~m}$, respectively, where the position stone artifacts were relatively concentrated. Moreover, samples for magnetic susceptibility, a proxy for palaeoenvironmental variations, were collected from the section at intervals of $10 \mathrm{~cm}$. These samples were dried at $38^{\circ} \mathrm{C}$ for $40 \mathrm{~h}$ and prepared for low-frequency magnetic susceptibility $(470 \mathrm{~Hz})$ measurements using a 
Batington MS-2 magnetic meter in the laboratory at Nanjing University.

The sample preparation for equivalent dose $\left(D_{e}\right)$ determination was conducted under dim red light in the laboratory. The two ends of the sample $(\sim 2-3 \mathrm{~cm})$ that might have been exposed to sunlight were removed to ascertain the environmental dose rate and water content. The rest of the sample was treated with $30 \% \mathrm{H}_{2} \mathrm{O}_{2}$ and $10 \% \mathrm{HCl}$ to remove organic matter and carbonates. Then, the 40-63 and 63-90 $\mu \mathrm{m}$ size fractions were separated by wet sieving. The 40-63 $\mu \mathrm{m}$ particles were used for quartz extraction and were immersed in $40 \% \mathrm{H}_{2} \mathrm{SiF}_{6}$ for two weeks to remove feldspar and then cleaned by using $10 \% \mathrm{HCl}$ for $40 \mathrm{~min}$. The purity of the isolated quartz was checked by the OSL IR depletion ratio method (Mejdahl et al., 1994; Duller, 2003). Samples were accepted until the influence of the IR stimulated luminescence (IRSL) signal could be neglected (i.e., IRSL/optical stimulated luminescence (OSL) $<10 \%$ ). The $63-90$ um particles were soaked in $10 \% \mathrm{HF}$ for $15 \mathrm{~min}$ to remove the wrap and outer layer affected by $\alpha$-ray and then cleaned by $10 \% \mathrm{HCl}$ for $20 \mathrm{~min}$. The feldspar particles were separated using a heavy liquid solution (density of $2.58 \mathrm{~g} / \mathrm{cm}^{-3}$ ). Subsequently, quartz grains were settled onto stainless steel discs in large aliquots ( $\sim 8 \mathrm{~mm}$ diameter $)$ and feldspar grains were settled in cups as small aliquots $(\sim 2 \mathrm{~mm}$ diameter $)$ with silicon oil.

All luminescence measurements were performed on a Risø TL/OSL reader (model DA-20) equipped with an accurately calibrated ${ }^{90} \mathrm{Sr} /{ }^{90} \mathrm{Y}$ beta source at the Luminescence Laboratory of Nanjing University. Blue light-emitting diodes (LEDs; $470 \mathrm{~nm}, \sim 80 \mathrm{~m} \mathrm{W.cm}{ }^{-2}$ ) were employed for quartz stimulation, whereas IR LEDs $\left(870 \mathrm{~nm}, \sim 135 \mathrm{~m} \mathrm{~W} . \mathrm{cm}^{-2}\right)$ were utilized to stimulate the feldspar (Bǿtter-Jensen et al., 2010). The quartz OSL signal was detected using a $7.5 \mathrm{~mm}$ Schott U-340 (UV) filter, whereas feldspar post-IR IRSL (pIRIR 290$)$ signals were detected using combined Corning 7-59 and Schott BG-39 filters. The environmental dose rate was obtained by measuring the radioactive dose of the sample. The radioactive elements (uranium (U), thorium (Th), and potassium $(\mathrm{K})$ ) in all the samples were determined using inductively coupled plasma mass spectrometry. Other factors, such as the measured water content (mass of moisture/dry mass) and contribution of cosmic rays (Prescott and Hutton (1994), were also considered in the final dose rate calculation. Small internal dose rates of $0.030 \pm 0.015$ and $0.06 \pm 0.03 \mathrm{~Gy} / \mathrm{ka}$ from $\mathrm{U}$ and $\mathrm{Th}$, respectively, were assumed for quartz and feldspar (Zhao and Li, 2005). For the 63-90 $\mu \mathrm{m}$ feldspar grains, an internal radioactivity from $\mathrm{K}$ and $\mathrm{Rb}$ contents was considered (Huntley and Baril, 1997). The element concentrations were converted into the final dose rate using the conversion parameters provided by Guérin et al. (2011).

Given the upper limit of dating, three methods were used to determine $D_{\mathrm{e}}$ : the single-aliquot regenerative-dose (SAR) protocol for quartz OSL dating, thermal transfer OSL (TT-OSL) and feldspar pIRIR 290 . The OSL dating method was validated for dating young sediments (Wintle and Murray, 2006). A standardized procedure (Murray and Wintle, 2000, $2003)$ using a preheat of $260^{\circ} \mathrm{C}(10 \mathrm{~s})$ and a cutheat of $220^{\circ} \mathrm{C}$ for the test dose before the 40 $\mathrm{s}$ blue stimulation at $125^{\circ} \mathrm{C}$ was employed in this study to detect the natural signal (Ln). The TT-OSL examines weak recuperative signals but effectively extends the dating limit (Wang et al., 2006, 2007a). The procedure provided by Stevens et al. (2009) was also performed. A special high-temperature blue-light bleach $\left(290^{\circ} \mathrm{C}\right.$ for $\left.400 \mathrm{~s}\right)$ was used to remove any remnant TT-OSL signal following the previous dosing. The pIRIR 290 procedure can effectively eliminate the effects of abnormal decay and obtain a reliable age (Thomsen et al., 2008; Jain 
and Ankjærgaard, 2011; Li and Li, 2011, 2012; Thiel et al., 2011; Buylaert et al., 2012; Zhang and $\mathrm{Li}, 2020$ ). In this study, the pIRIR 200,290 protocol was used to determine $\mathrm{D}_{\mathrm{e}}$. The preheating temperatures of the regenerative and test doses were both $320^{\circ} \mathrm{C}$ for $60 \mathrm{~s}$. After the $200^{\circ} \mathrm{C}$ low-temperature IR stimulation, IR light at $290^{\circ} \mathrm{C}$ was used to eliminate the abnormal decay of feldspar (Thiel et al., 2011; Buylaert et al., 2012).

\subsection{Results}

NJU2572, NJU2574, and NJU2578 were measured by quartz OSL. The quartz samples generated a bright and fast-decaying natural OSL signal (Figures 3a and 3b). The decay curves of NJU2572 and NJU2574 quickly decreased to near zero in the initial $1.28 \mathrm{~s}$ stimulation. These results suggest that our samples were dominated by the fast component. The recycling ratio and recuperation of the two samples ranged from 0.94 to 1 and $0 \%$ to $0.1 \%$, respectively, consistent with the criteria of acceptance. The dose-response curve (DRC) was fitted using a single exponential function. The DRC of NJU2572 fit well and showed linear growth, implying that the signals were far from saturation. However, the signals of NJU2574 and NJU2578 were saturated. As revealed in Figure 3b, the DRC plot of NJU2574 appeared to be flat, and the natural signal $\left(\mathrm{L}_{\mathrm{x}} / \mathrm{T}_{\mathrm{x}}\right)$ reached $80 \%-90 \%$ of the saturation value (i.e., $\left.2 \mathrm{D}_{0}\right)$. In addition, the natural signal of NJU2578 was approximately $85 \%-90 \%$ above the saturation value, with an aliquot exceeding $2 \mathrm{D}_{0}$. Therefore, the $\mathrm{D}_{\mathrm{e}}$ values of NJU2574 and NJU2578
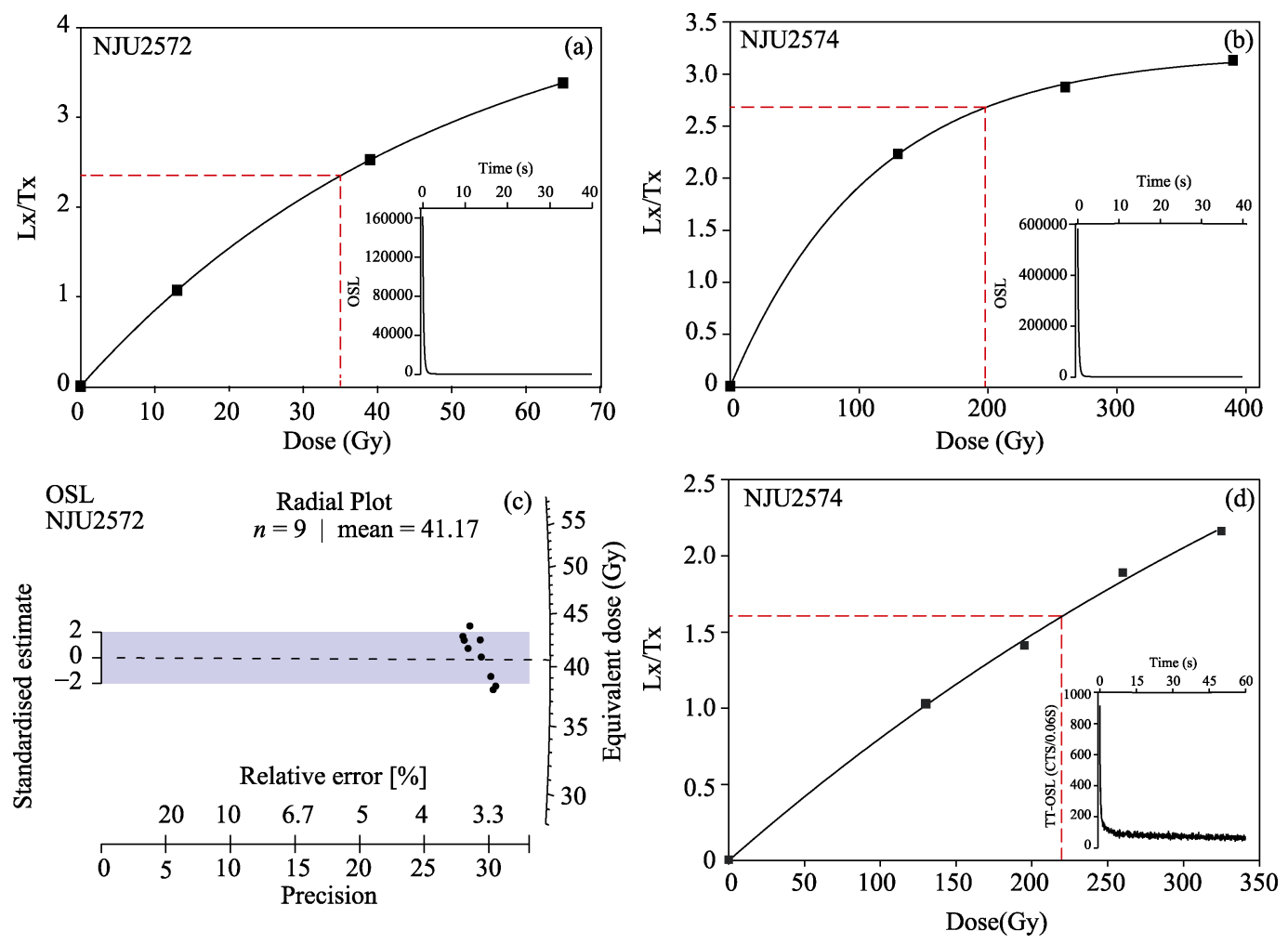

Figure 3 (a) and (b) DRC acquired using the quartz OSL for samples NJU2572 and NJU2574; (c) radial plot of quartz aliquots obtained by OSL for sample NJU2572; (d) DRC acquired with the quartz TT-OSL for sample NJU2574 (The inset of (a), (b) and (d) shows the decay curves of the natural signal) 
determined by OSL were underestimates (Wintle and Murray, 2006; Nian et al., 2013; Wintle and Adamiec, 2017). Thirteen aliquots of NJU2572 were examined. The $\mathrm{D}_{\mathrm{e}}$ displayed a normal distribution, and the average values were feasible for the final $\mathrm{D}_{\mathrm{e}}$. After eliminating the two maxima and two minima that deviated by approximately $20 \%$ from the mid-value, the $\mathrm{D}_{\mathrm{e}}$ values of the remaining nine aliquots of NJU2572 were clustered at approximately 38-44 Gy (Figure 3c).

All samples were measured by TT-OSL to determine their $\mathrm{D}_{\mathrm{e}}$ values. The inset indicates that the TT-OSL signal of NJU2574 decayed quickly and was dominated by the fast components (Figure 3d). The DRC of NJU2574 showed a robust linear upward trend (Figure 3d), thereby suggesting a good dating potential. The deposit at the LSM section was composed of fine clay particles that had experienced weak hydrodynamic conditions, implying that the quartz grains were well sorted and bleached. For the aliquots of all samples $(n=25)$, the recycling ratio was between 0.9 and 1.1, except for one aliquot of NJU2578 (0.8); further, the recuperation was below $1.4 \%(<5 \%)$. The $\mathrm{D}_{\mathrm{e}}$ values of each sample showed a normal distribution, indicating that the mean values of the accepted aliquots could be used as the final $\mathrm{D}_{\mathrm{e}}$ values for each sample. For the accepted samples of NJU2578, any maximum ( 440.4 Gy) and minimum $(\sim 162.7 \mathrm{~Gy}) \mathrm{D}_{\mathrm{e}}$ values with large discrepancies from the mid-values were disregarded. The $\mathrm{D}_{\mathrm{e}}$ values from the remaining five aliquots acquired by TT-OSL were not as concentrated as those acquired by OSL but were within the standardized estimation, with a relative $\mathrm{D}_{\mathrm{e}}$ error $<10 \%$ (Figure $4 \mathrm{c}$ ). The average $\mathrm{D}_{\mathrm{e}}$ of NJU2574 was approximately $223 \mathrm{~Gy}$, which is a bit higher than that of the samples measured by OSL. The mean $\mathrm{D}_{\mathrm{e}}$ of NJU2572
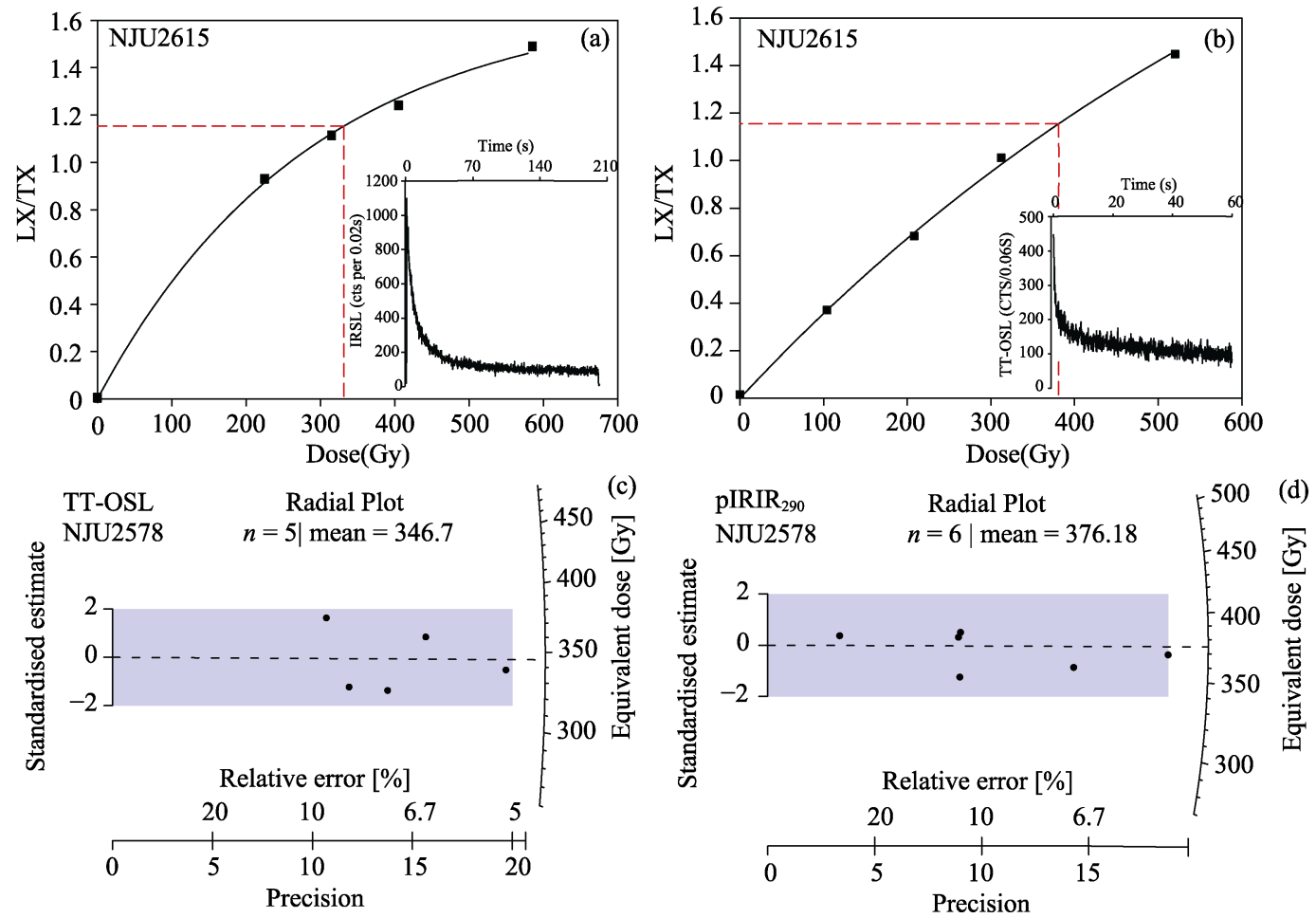

Figure 4 (a) and (b) DRC obtained using TT-OSL and pIRIR 290 for sample NJU2615 (The inset shows the decay curves.); (c) and (d) radial plot for NJU2578, using quartz TT-OSL and feldspar pIRIR 290 , respectively 
was consistent with the OSL results and showed no large discrepancy.

The IRIR $_{290}$ protocol was also used for all samples, but the $\mathrm{D}_{\mathrm{e}}$ value was obtained for NJU2578 at $2.75 \mathrm{~m}$ depth and for NJU2615 at the bottom of the LSM section. The pIRIR signals for NJU2572, NJU2574, NJU2576, and NJU2577 were dim and dispersed. A total of 21 aliquots were tested for two samples (11 aliquots for NJU2578 and 10 for NJU2615). Five aliquots of NJU2578 and four aliquots of NJU2615 were rejected after examining the recycling ratio and recuperation results. As illustrated in Figures $4 \mathrm{a}$ and $4 \mathrm{~b}$, the IRSL signal of NJU2615 was brighter than its TT-OSL counterpart. The DRC of NJU2615 continually increased up to $600 \mathrm{~Gy}$, which also indicated its dating potential. The $\mathrm{D}_{\mathrm{e}}$ values ascertained using feldspar from NJU2578 (Figure 4d) were distributed at different precision locations and were more scattered than those obtained using quartz TT-OSL. This result may be attributed to the unstable and weak feldspar signal of these samples, which possibly hindered the acquisition of reliable results for several aliquots. Finally, we used the mean $\mathrm{D}_{\mathrm{e}}$ values of 376 and 412 Gy for NJU2578 and NJU2615, respectively, as references.

\subsection{Magnetic susceptibility and dose rate}

The magnetic susceptibility of the LSM profile decreased with depth (Figure 5). The susceptibility decreased considerably above $1 \mathrm{~m}$ and decreased and stabilized below $1 \mathrm{~m}$. The stratigraphy of the profile showed that the reticulated pattern also disappeared at a depth of $1 \mathrm{~m}$. Previous research has shown that the magnetic susceptibility of the reticulated red clay and leached palaeosol layers in the middle and lower reaches of the Yangtze River is generally lower than those measured on the Loess Plateau (Ji and Xia, 2007; Mao et al., 2008; Zhu et al., 2011; Yang et al., 2015; Zhang et al., 2018). This condition may be related to the loss of magnetic minerals or weathering due to precipitation leaching. Similarly, the LSM profile experienced eluviation, which weakened the magnetic susceptibility below $1 \mathrm{~m}$ depth and

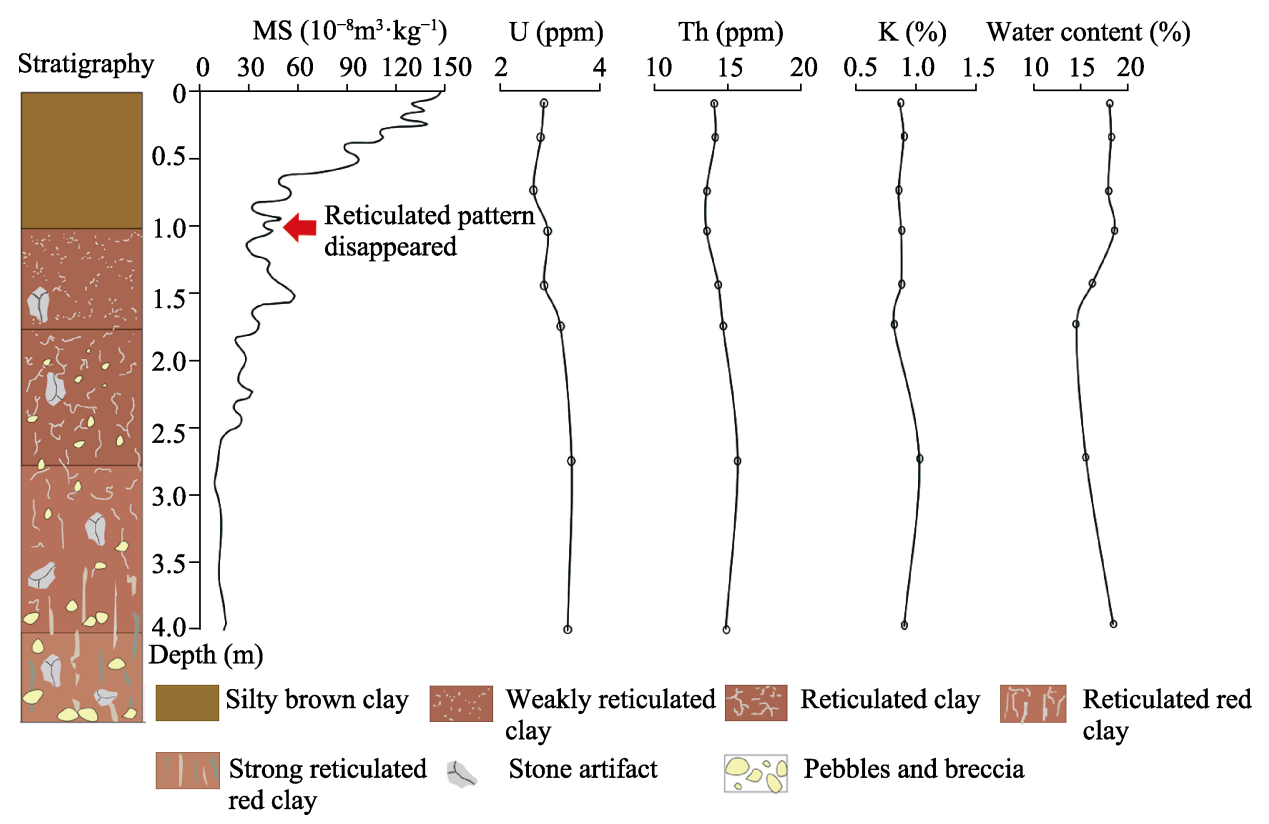

Figure 5 Curves of the magnetic susceptibility, radiation dose (U, Th, and K), and water content 
reflected a humid climate, as shown by earlier studies on the Qinling loess deposits (Zhao et al., 2008; Lu et al., 2011b; Sun et al., 2017a). Thus, the magnetic susceptibility of the reticulated red clay is not only a climate proxy but also represents an important boundary between the reticulated red clay and overlying loess deposits.

Earlier studies on red clays in South China indicated that weathering eluviation causes the enrichment of $\mathrm{U}$, which results in overestimations of the dose rate (Zhang et al., 2007; Han et al., 2012). In the LSM section, the U, Th, and $\mathrm{K}$ contents slightly increased below $1.5-1.75 \mathrm{~m}$, but this caused no marked disturbance in the radioactive elements and the final dose rate. As illustrated in Figure 5, the $U$ and Th contents varied over the ranges of 2.67-3.44 and 13.6-15.7 ppm, respectively, whereas $\mathrm{K}$ ranged between $0.82 \%$ and $1.03 \%$; the values were all constant within a $10 \%$ range of error (Zhang et al., 2019). The water content, another significant and influential factor, was stable and uniform and concentrated at $18 \%-19 \%$ with an average value of $17.27 \%$. In general, the radioactive element and water contents were constant and caused a minimal effect on dose rates. The environmental dose rates of other samples ranged from $\sim 2.3 \mathrm{~Gy} / \mathrm{ka}$ to $\sim 2.48 \mathrm{~Gy} / \mathrm{ka}$, except in NJU2578. The relatively high dose rate of NJU2578 ( 2.73 Gy/ka) might be attributed to its high $\mathrm{U}$ and K contents, whereas its relative error was acceptable within $10 \%$. The dose rates of all samples remained constant, with an average of $2.49 \mathrm{~Gy} / \mathrm{ka}$. Table 1 shows the U, Th, K contents, dose rates, and $D_{e}$ values obtained using the three luminescence dating methods and the age of each sample.

Table 1 Dating results of quartz OSL, TT-OSL, and feldspar pIRIR 290 dating methods

\begin{tabular}{|c|c|c|c|c|c|c|c|c|c|c|c|c|c|}
\hline \multirow{2}{*}{ Lab No. } & \multirow{2}{*}{$\begin{array}{l}\text { Depth } \\
\text { (m) }\end{array}$} & \multirow{2}{*}{$\begin{array}{l}\mathrm{wc} \\
(\%)\end{array}$} & \multirow{2}{*}{$\mathrm{U}(\mathrm{ppm})$} & \multirow{2}{*}{ Th (ppm) } & \multirow{2}{*}{$\mathrm{K}(\%)$} & \multicolumn{2}{|c|}{ Dose rate (Gy/ka) } & \multicolumn{3}{|c|}{$\mathrm{D}_{\mathrm{e}}(\mathrm{Gy})$} & \multicolumn{3}{|c|}{ Age (ka) } \\
\hline & & & & & & OSL \& TT & $\operatorname{IIRIR}_{290}$ & OSL & TT-OSL & $\mathrm{pIRIR}_{290}$ & OSL & TT-OSL & $\mathrm{pIRIR}_{290}$ \\
\hline NJU2572 & 0.10 & 18.2 & $2.88 \pm 0.11$ & $14.1 \pm 0.38$ & $0.87 \pm 0.04$ & $2.44 \pm 0.11$ & - & $41.7 \pm 1.4$ & $47.0 \pm 7.6$ & - & $17.1 \pm 1.0$ & $19.9 \pm 3.4$ & - \\
\hline NJU2574 & 0.75 & 18.0 & $2.67 \pm 0.10$ & $13.6 \pm 0.38$ & $0.86 \pm 0.04$ & $2.30 \pm 0.11$ & - & $>217$ & $222.5 \pm 4.8$ & - & $>94$ & $96.8 \pm 5.4$ & - \\
\hline NJU2576 & 1.45 & 16.3 & $2.89 \pm 0.11$ & $14.4 \pm 0.39$ & $0.88 \pm 0.04$ & $2.42 \pm 0.12$ & - & - & $291.4 \pm 39.4$ & - & - & $120.3 \pm 17.5$ & - \\
\hline NJU2577 & 1.75 & 14.6 & $3.21 \pm 0.12$ & $14.7 \pm 0.40$ & $0.82 \pm 0.04$ & $2.48 \pm 0.12$ & - & - & $311.1 \pm 45.1$ & - & - & $125.6 \pm 19.4$ & - \\
\hline NJU2578 & 2.75 & 15.6 & $3.44 \pm 0.12$ & $15.7 \pm 0.42$ & $1.03 \pm 0.04$ & $2.73 \pm 0.13$ & $.20 \pm 0.13$ & $>331$ & $346.7 \pm 17.3$ & $376 \pm 14$ & $>121$ & $126.9 \pm 9.3$ & $118 \pm 7$ \\
\hline NJU2615 & 4.00 & 18.6 & $3.36 \pm 0.13$ & $14.9 \pm 0.42$ & $0.91 \pm 0.04$ & $2.47 \pm 0.12$ & $.00 \pm 0.12$ & - & $358.7 \pm 24.6$ & $412 \pm 42$ & - & $145.5 \pm 12.5$ & $167 \pm 18$ \\
\hline
\end{tabular}

" ">" means saturated age estimation; "wc" = water content

\section{Discussion}

\subsection{Chronological sequence}

The ages obtained from the quartz OSL, TT-OSL, and feldspar pIRIR 290 dating methods increased with depth (Figure 6). The OSL and TT-OSL ages of the youngest sample (NJU2572) at the top of the section were consistent, at $17.1 \pm 1.0$ and $19.9 \pm 3.4 \mathrm{ka}$, respectively. The OSL age of NJU2574 at $0.75 \mathrm{~m}$ was older than $94 \mathrm{ka}$, and its TT-OSL age was $96.8 \pm 5.4 \mathrm{ka}$, which constrained the age to between 94 and $102 \mathrm{ka}$. NJU2576 and NJU2577 were $0.3 \mathrm{~m}$ apart, yielding TT-OSL ages of $120.3 \pm 17.5$ and $125.6 \pm 19.4 \mathrm{ka}$, respectively. The age errors of NJU2576 and NJU2577 were $>10 \%$ because the extracted quartz was insufficient for additional measurements. However, the ages were consistent with the chronological se- 
quence. Various ages were obtained for sample NJU2578 using the three methods. The minimum age obtained by the OSL was $121 \mathrm{ka}$, suggesting that the layers below this sample accumulated before $121 \mathrm{ka}$. The quartz TT-OSL age of NJU2578 was $126.9 \pm 9.3 \mathrm{ka}$, which was slightly older than that given by feldspar. The TT-OSL and feldspar ages of sample NJU2615, which was sampled from the bottom of the section, were $145.5 \pm 12.5$ and $167 \pm$ $18 \mathrm{ka}$, respectively. The TT-OSL age was slightly younger than the feldspar age. The results obtained using TT-OSL and pIRIR protocols were identical in terms of age errors. Therefore, the TT-OSL and pIRIR 290 methods can be used to check their respective age results. The deposits at the LSM section were composed of fine clay particles that were deposited under weak hydrodynamic conditions. The quartz TT-OSL ages corresponded with the feldspar pIRIR $_{290}$ ages. These results imply that the quartz and feldspar were well bleached. However, the unstable signal and relatively scattered $\mathrm{D}_{\mathrm{e}}$ values from the feldspar reduced the chronological accuracy. Finally, the quartz OSL and TT-OSL ages were used to constrain the final ages of the site.

In summary, the samples dated from $145.5 \pm 12.5 \mathrm{ka}$ to $17.1 \pm 1.0 \mathrm{ka}$, and the ages extended from the Late-Middle Pleistocene to the Late-Late Pleistocene. According to the OSL and TT-OSL ages of NJU2574, the upper age limit of the reticulated clay layer is approximately 94-102 ka, which indicates that the boundary of the Quaternary reticulated red clay formed in the Early-Late Pleistocene. The cultural layer was deposited between 150 and $100 \mathrm{ka}$, during the Late-Middle Pleistocene.

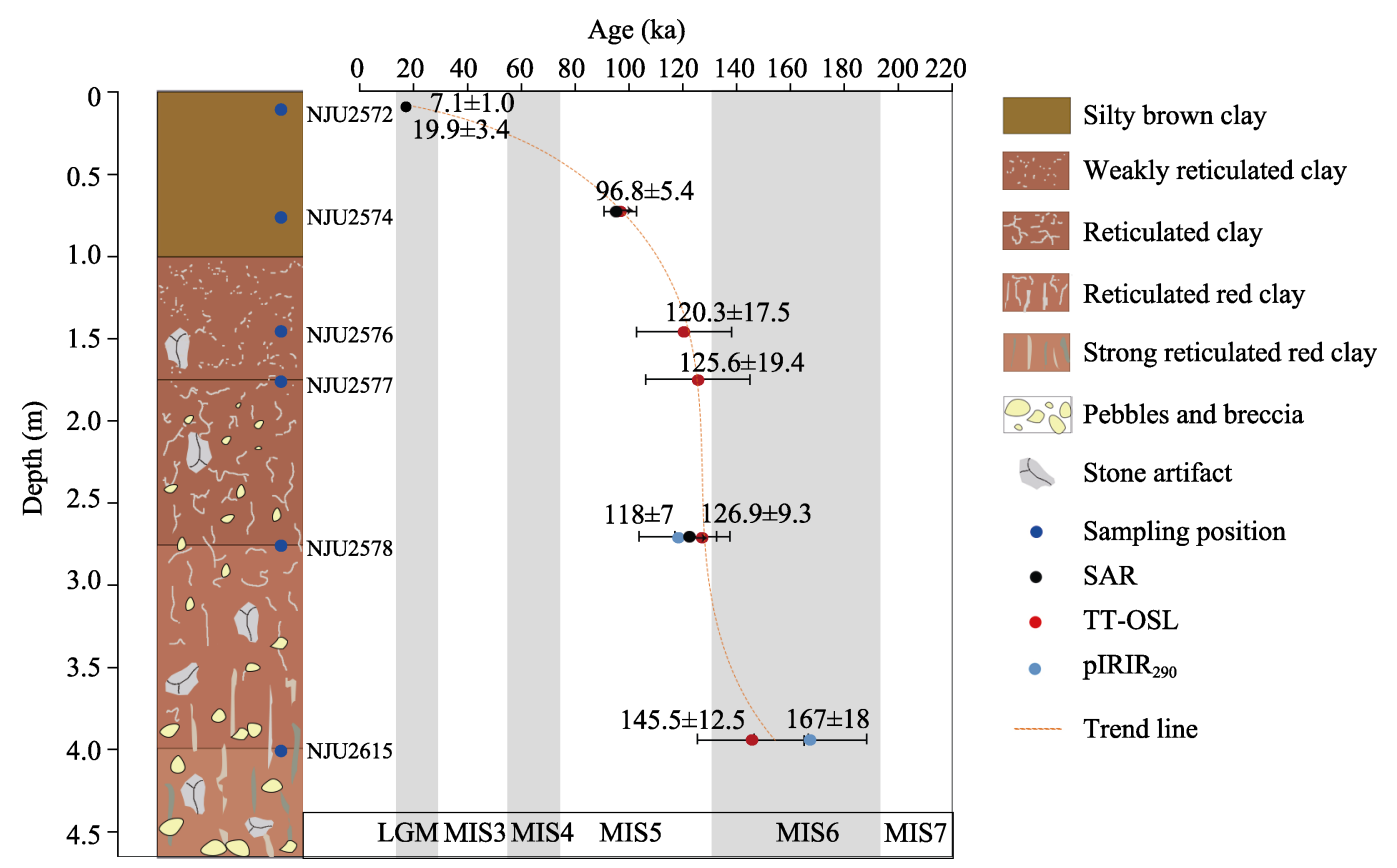

Figure 6 The LSM section, ages, and the cultural layer correspondence to marine oxygen isotopic stages

\subsection{Correlation with QLT and YDG palaeolithic sites}

Most palaeolithic industries in Zhejiang Province belonged to the southern main industry, which was characterized by direct hammer percussion methods and simple tools made of 
pebbles and large pieces, such as those found in the QLT (Figure 1, No.5) and YDG sites (Figure 1, No.3) in China. In the QLT site, approximately 200 palaeolithic artifacts belonging to the upper cultural layer were buried in Xiashu loess and were estimated to date to the late stage of the Middle Pleistocene based on stratigraphic correlation (Guan et al., 2018). Half of the artifacts were simple and large and coexisted with small flakes and scrapers, which were also identified as the chopper-chopping tool tradition in South China or were placed under "Mode 1" industry, with minimal modification (ZPICRA, 2009; Guan et al., 2018). Compared with the results of the QLT site, the proportion of small-sized flakes and scrapers at the YDG site increased to $89.2 \%$, and the number of artifacts using flint as the raw material sharply increased (accounting for $44.2 \%$ ). Therefore, the upper cultural layer of the YDG site might have existed in the Late Pleistocene based on stratigraphic correlation (ZPICRA, 2009).

The miniaturisation of stone artifacts at the YDG site is evidently similar to the conditions observed at the LSM site. Stone artifacts at the LSM site also consisted of flint. However, bipolar techniques were only applied at the YDG sites, whereas the hammer percussion technique was used only at the QLT and LSM sites. The LSM site was in the same age range as the upper cultural layer of the QLT site. Therefore, the LSM site can be regarded as a supplementary material for the Middle to Late Palaeolithic industry in Zhejiang Province during the late stage of the Middle Pleistocene to Late Pleistocene. Our detailed luminescence dating results are essential for setting the chronological sequence of palaeolithic industry in Zhejiang Province.

\subsection{Environmental implication}

Pebbles and breccia coexisted with the artifacts and disappeared at approximately $1.75 \mathrm{~m}$ on the LSM section (top of Layer 3) (Figure 6). Under a high-energy hydrodynamic environment, water could have occasionally carried large pebbles to the site. Under a low-energy hydrodynamic environment, water flow would have been weakened, silt and clay deposited, and aeolian sediment enhanced, thereby resulting in fine-matter accumulation. The deposit at the LSM section was composed of fine clay particles that were deposited under extremely weak hydrodynamic conditions. Consequently, the stone artifacts of the LSM site may reflect hominin activities on the floodplain spanning a long period of time. However, we cannot dismiss possibility that hominins transferred pebbles to the LSM section.

The age range of LSM site mainly corresponded to transition from MIS6 to MIS5, thereby implying that hominins lived in both glacial and interglacial stages. For the relatively steady glacial period, pollen analyses of Late Quaternary boreholes in the Yangtze River Delta (Wang et al., 2008) have revealed that the climate at the MIS6 stage might have been cool and dry, resulting in a relatively open or mosaic habitat. Studies of hominins and environmental evolution around the world generally posit that hominins were possibly adapted for survival in relatively open environments, and they expanded their habitats from an originally closed environment (Cerling et al., 2011; Cuenca-Bescós et al., 2011; Serrano et al., 2015; Sémah et al., 2016; Muttoni et al., 2018). Correspondingly, hunting acquisition tools might have been adapted to environmental changes (Moncel et al., 2018). Therefore, the LSM site proves that during the glacial period, the lower reaches of the Yangtze River were suitable for the survival of hominins and indicates that the transition from the MIS6 
glacial period to the MIS5 interglacial period was probably associated with changes in palaeolithic industries and hominin behaviours in response to climate change. In correlation with the QLT and YDG palaeolithic sites, the LSM cultural layer, which was dominated by small-sized stone flakes and cores, may show miniaturisation of artifacts due to a cooling glacial environment. However, additional evidence is needed to support this interpretation.

\section{Conclusion}

This study indicated that multiple protocols of luminescence dating methods, namely, OSL, TT-OSL, and pIRIR 290 , are applicable for the LSM palaeolithic site, which is buried by reticulated clay. The results showed that the LSM section developed before $145.5 \pm 12.5 \mathrm{ka}$ and ended after $17.1 \pm 1.0 \mathrm{ka}$. The OSL and TT-OSL ages of NJU2574 ranged from 94 to $96.8 \pm 5.4 \mathrm{ka}$ and provide a possible absolute age of approximately 94-100 ka for the upper boundary of the reticulated red earth. This finding also proves that the reticulated red clay in this area developed in the Late Pleistocene. The feldspar ages of the lower two samples were disregarded due to their poor luminescence performances. Based on the TT-OSL ages, the artifact assemblages buried entirely in the reticulated red clay dated to approximately 150 to $100 \mathrm{ka}$ and corresponded to stage of transition between MIS6 and MIS5. The luminescence dating results confirmed the presence of hominin activity in the glacial period at the late stage of the Middle Pleistocene in southern China. An independent chronological reference was added for further study of the evolution of palaeolithic industry in Zhejiang Province.

\section{Acknowledgements}

We thank Zeng Qiongxuan, Xu Xinghua, and Lu Yiming for their assistance.

\section{References}

An Z S, Gao W Y, Zhu Y Z et al., 1990. Magnetostratigraphic dates of Lantian Homo erectus. Acta Anthropologica Sinica, 9 (1): 1-7. (in Chinese)

Bǿtter-Jensen L, Thomsen K J, Jain M, 2010. Review of optically stimulated luminescence (OSL) instrumental developments for retrospective dosimetry. Radiation Measurements, 45(3-6): 253-257.

Buylaert J, Jain M, Murray A S et al., 2012. A robust feldspar luminescence dating method for Middle and Late Pleistocene sediments. Boreas, 41(3): 435-451.

Cerling T E, Wynn J G, Andanje S A et al., 2011. Woody cover and hominin environments in the past 6 million years. Nature, 476(4): 51-56.

Chen T M, Yuan S X, Gao S J, 1984. The study on uranium-series dating of fossil bones and absolute age sequence for the main Paleolithic sites of North China. Acta Anthropologica Sinica, 3: 259-269. (in Chinese)

Cuenca-Bescós G, Melero-Rubio M, Rofes J et al., 2011. The Early-Middle Pleistocene environmental and climatic change and the human expansion in Western Europe: A case study with small vertebrates (Gran Dolina, Atapuerca, Spain). Journal of Human Evolution, 60(4): 481-491.

Deng C L, Hao Q Z, Guo Z T et al., 2019. Quaternary integrated stratigraphy and time frame in China. Science China: Earth Sciences, 49(1): 330-352. (in Chinese)

Duller G A T, 2003. Distinguishing quartz and feldspar in single grain luminescence measurements. Radiation Measurements, 37(2): 161-165.

Gao X, 2019. Seventy years of exploration: A review and prospect of Paleolithic archaeology in China. China Cultural Relics News, (5). (in Chinese)

Guérin G, Mercier N, Adamiec G, 2011. Dose-rate conversion factors: Update. Ancient TL, 29(1): 5-8.

Guan Y, Xu X, Kuman K et al., 2018. The absence of Acheulean: Qiliting mode 1 site and the mode 1 occupations 
in southeast China. Quaternary International, 480(30): 152-165.

Guo H J, Chen S H, Zhou J Z et al., 2016. A brief report on Paleolithic archaeological survey of Deqing in 2016. Cultural Relics of the East, (4): 1-5. (in Chinese)

Guo Y, Li B, Zhang J et al., 2016. Luminescence ages for three 'Middle Palaeolithic' sites in the Nihewan Basin, northern China, and their archaeological and palaeoenvironmental implications. Quaternary Research, 85(3): 456-470.

Guo Y, Li B, Zhang J et al., 2017. New ages for the Upper Palaeolithic site of Xibaimaying in the Nihewan Basin, northern China: Implications for small-tool and microblade industries in North-east Asia during marine isotope stages 2 and 3. Journal of Quaternary Science, 32(4): 540-552.

Han Z Y, Li X S, Chen Y et al., 2012. The top boundary age of the reticulated layer in Binshaling area of Poyang Lake. Scientia Geographica Sinica, 32(1): 110-115. (in Chinese)

$\mathrm{Hu}$ Y, Marwick B, Zhang J et al., 2018. Late Middle Pleistocene Levallois stone-tool technology in southwest China. Nature, 565: 82-85.

Huang X K, Luo B N, Zhou L P, 2019. Luminescence signals from polymineral fine-grains in strongly chemically-weathered sediments from a paleolithic site and their usefulness for dating. Quaternary Science, 39(2): 438-447. (in Chinese)

Huang Z G, 1999. The change of natural zones and the evolution of red earth in China. Acta Geographica Sinica, 54(3): 193-203. (in Chinese)

Huntley D J, Baril, M R, 1997. The K content of the K-feldspars being measured in optical dating or in thermoluminescence dating. Ancient TL, 15(1): 11-13.

Jain M, Ankjaergaard C, 2011. Towards a non-fading signal in feldspar: Insight into charge transport and tunnelling from time-resolved optically stimulated luminescence. Radiation Measurements, 46(3): 292-309.

Ji Y P, Xia Z K, 2007. Comparison and primarily interpretation of magnetic susceptibilities in different sediments. Acta Geoscientica Sinica, 28(6): 541-549. (in Chinese)

Lai Z P, Zhou J, Xia Y F et al., 2001. Luminescence geochronology of Xiashu loess near Nanjing. Journal of Desert Research, 21(2): 203-207. (in Chinese)

Li B, Li S H, 2011. Luminescence dating of K-feldspar from sediments: A protocol without anomalous fading correction. Quaternary Geochronology, 6(5): 468-479.

Li B, Li S H, 2012. Luminescence dating of Chinese loess beyond $130 \mathrm{ka}$ using the non-fading signal from K-feldspar. Quaternary Geochronology, 10: 24-31.

Liu C, Deng C, 2011. Advances in chronological research of magnetic strata in southern China. Frontiers in Earth Sciences, 18(4): 158-170. (in Chinese)

Liu C, Xu X, Yuan B Y et al., 2008. Magnetostratigraphy of the Qiliting section (SE China) and its implication for geochronology of the red soil sequences in southern China. Geophysical Journal International, 1(174): $107-117$.

Liu T, 1985. Loess and the Environment. Beijing: China Ocean Press.

Lu H Y, Sun X, Wang S et al., 2011a. Ages for hominin occupation in Lushi basin, middle of South Luo River, Central China. Journal of Human Evolution, 60(5): 612-617.

Lu H Y, Zhang H Y, Wang S J et al., 2007. A preliminary survey on loess deposit in Eastern Qinling Mountains (Central China) and its implication for estimating age of the Pleistocene lithic artifacts. Quaternary Science, 27(4): 559-567. (in Chinese)

Lu H Y, Zhang H Y, Wang S J et al., 2011b. Multiphase timing of hominin occupations and the paleoenvironment in Luonan Basin, Central China. Quaternary Research, 76(1): 142-147.

Lu H Y, Zhuo H X, Zhang W C et al., 2017. Earth surface processes and their effects on human behavior in monsoonal China during the Pleistocene-Holocene epochs. Journal of Geographical Sciences, 27(11): 33-46.

Mao L J, Mo W D, Jiang L P et al., 2008. Environmental change since mid-Pleistocene recorded in Shangshan achaeological site of Zhejiang. Journal of Geographical Sciences, 18(2): 247-256.

Mejdahl V, Bǿtter-Jensen L, 1994. Luminescence dating of archaeological materials using a new technique based on single aliquot measurements. Quaternary Science Review, 13(5-7): 551-554.

Murray A S, Wintle A G, 2000. Luminescence dating of quartz using an improved single-aliquot regenerative-dose protocol. Radiation Measurements, 32(1): 57-73.

Murray A S, Wintle A G, 2003. The single aliquot regenerative dose protocol: potential for improvements in reli- 
ability. Radiation Measurements, 37(4/5): 377-381.

Muttoni G, Scardia G, Kent D V, 2018. Early hominins in Europe: The Galerian migration hypothesis. Quaternary Science Review, 180(1): 1-29.

Nian X M, Gao X, Xie F et al., 2014a. Chronology of the Youfang site and its implications for the emergence of microblade technology in north China. Quaternary International, 347(9): 113-121.

Nian X M, Gao X, Zhou L P, 2014b. Chronological studies of Shuidonggou (SDG) Locality 1 and their significance for archaeology. Quaternary International, 347(9): 5-11.

Nian X M, Li F, Chen F Y, Zhang W G et al., 2016. Optically stimulated luminescence ages for human occupation during the penultimate glaciation in the western Loess Plateau of China, Journal of Quaternary Science, 31(8): 928-935.

Nian X M, Zhou L P, Yuan B Y, 2013. Optical stimulated luminescence dating of terrestrial sediments in the Nihewan basin and its implication for the evolution of ancient Nihewan lake. Quaternary Research, 33(3): 403-414. (in Chinese)

Prescott J R, Hutton J T, 1994. Cosmic ray contributions to dose rates for luminescence and ESR dating: Large depths and long-term time variations. Radiation Measurements, 23(2/3): 497-500.

Qiao Y S, Guo Z T, 2003. Study on magnetic stratigraphy of wind-dust accumulation-soil sequence in southern Anhui and its paleoenvironmental significance. Chinese Science Bulletin, 48(13): 1465-1469. (in Chinese)

Qin J T, Zhou L P, 2007. Optically stimulated dating of upper part of a thick loess section at Caoxian near the northern desert of China. Quaternary Science, 27(4): 546-552.

Sémah A, Sémah F, Moigne A et al., 2016. The palaeoenvironmental context of the Palaeolithic of Java: A brief review. Quaternary International, 416(19): 38-45.

Serrano E, Gómez-Lende M, González-Amuchastegui M J et al., 2015. Glacial chronology, environmental changes and implications for human occupation during the Upper Pleistocene in the Eastern Cantabrian Mountains. Quaternary International, 364(7): 22-34.

Stevens T, Buylaert J P, Murray A S, 2009. Towards development of a broadly-applicable SAR TT-OSL dating protocol for quartz. Radiation Measurements, 44(5/6): 639-645.

Sun X, Jia X, Lu H et al., 2017a. A modified depositional hypothesis of the Hanjiang loess in the southern Qinling Mountains, Central China. Progress in Physical Geography: Earth and Environment, 41(6): 775-787.

Sun X, Li Y, Feng X et al., 2016. Pedostratigraphy of aeolian deposition near the Yunxian Man site on the Hanjiang River terraces, Yunxian basin, Central China. Quaternary International, 400(2): 187-194.

Sun X, Lu H, Wang S et al., 2012. Ages of Liangshan Paleolithic sites in Hanzhong Basin, Central China. Quaternary Geochronology, 10: 380-386.

Sun X, Lu H, Wang S et al., 2013. TT-OSL dating of Longyadong Middle Paleolithic site and paleoenvironmental implications for hominin occupation in Luonan Basin (central China). Quaternary Research, 79(2): 168-174.

Sun X, Lu H, Wang S et al., 2014. Age of newly discovered paleolithic assemblages at Liuwan site Louann basin, Central China. Quaternary International, 347(347): 193-199.

Sun X, Lu H, Wang S et al., 2017b. Early human settlements in the southern Qinling Mountains, Central China. Quaternary Science Review, 164(15): 168-186.

Sun X, Lu H, Wang S et al., 2018. Hominin distribution in glacial-interglacial environmental changes in the Qinling Mountains Range, Central China. Quaternary Science Review, 198(15): 37-55.

Sun X, Mercier N, Falgueres C et al., 2010. Recuperated optically stimulated luminescence dating of middle-size quartz grains from the Paleolithic site of Bonneval (Eure-Et-Loir, France). Quaternary Geochronology, 5(2/3): 342-347.

Thiel C, Buylaert J, Murray A et al., 2011. Luminescence dating of the Stratzing loess profile (Austria): Testing the potential of an elevated temperature post-IR IRSL protocol. Quaternary International, 234(1/2): 23-31.

Thomsen K J, Murray A S, Jain M, 2008. Laboratory fading rates of various luminescence signals from feldspar-rich sediment extracts. Radiation Measurements, 43(9/10): 1474-1486.

Wang K X, Xu X H, Sun X F et al., 2019. Cosmogenic nuclide burial dating of Liuwan Paleolithic site in the Luonan Basin, Central China. Journal of Geographical Sciences, 29(3): 406-416.

Wang S J, Lu H Y, 2016. Taphonomic and paleoenvironmental issues of the Pleistocene loessic Paleolithic sites in the Qinling Mountains, central China. Science China Earth Sciences, 46(7): 881-890. (in Chinese)

Wang S J, Lu H Y, Zhang H Y et al., 2014. Paleolithic tools and their dating in newly discovered loess layers in 
Lantian, Shaanxi. Science Bulletin, 59(14): 1318-1326. (in Chinese)

Wang S J, Lu H Y, Zhang H Y et al., 2008. Paleolithic and loess deposits found in the middle reaches of the Nanluo River in the East Qinling Mountains. Quaternary Research, 28(6): 988-999. (in Chinese)

Wang S J, Shen C, Hu S M, 2005. Lithic artefacts collected from open-air sites during 1995-1999 investigations in Luonan basin, China. Acta Anthropologica Sinica, 24(2): 87-103. (in Chinese)

Wang X L, Wintle A G, Lu Y C, 2006. Thermally transferred luminescence in fine-grained quartz from Chinese loess: basic observations. Radiation Measurements, 41: 649-658.

Wang X L, Wintle AG, Lu YC, 2007. Testing a single-aliquot protocol for recuperated OSL dating. Radiation Measurements, 42(3): 380-391.

Wang Z H, Zhao B C, Chen J et al., 2008. Preliminary discussion of stratigraphic framework and two transgressions in the late Quaternary in the Yangtze River Delta. Journal of Palaeogeography, 10(1): 99-110. (in Chinese)

Wintle A G, Adamiec G, 2017. Optically stimulated luminescence signals from quartz: A review. Radiation Measurements, 98: 10-33.

Wintle A G, Murray A S, 2006. A review of quartz optically stimulated luminescence characteristics and their relevance in single-aliquot regeneration dating protocols. Radiation Measurements, 41(4): 369-391.

Xiao J, Jin C, Zhu Y, 2002. Age of the fossil Dali Man in north-central China deduced from chronostratigraphy of the loess-paleosol sequence. Quaternary Science Review, 21(20-22): 2191-2198.

Xiong S F, Liu T S, Ding Z L, 2000. The weathering sequence of the red earth over southern China. Journal of Mountain Science, 18(1): 7-12. (in Chinese)

Xu X M, 2008. A review of Paleolithic archaeology in Zhejiang. Southeast Culture, (2): 6-10. (in Chinese)

Yang L H, Ye W, Zheng X M et al., 2015. The magnetic characteristics comparison of sedimentary red clay and laterite weathering crust in subtropical China. Scientia Geographica Sinica, 35(11): 1475-1481. (in Chinese)

Yang X Y, Xia Z K, Liu D S, 2005. Loess research and paleolithic archeology. Quaternary Research, 25(4): 461-466. (in Chinese)

Yi S, Li X, Han Z et al., 2018. High resolution luminescence chronology for Xiashu loess deposits of southeastern China. Journal of Asian Earth Science, 155(15): 188-197.

Yin Q Z, Guo Z T, 2006. Reticulated laterite in southern China and the unusually strong period of the East Asian monsoon. Science Bulletin, 51(2): 186-193. (in Chinese)

Yuan B Y, Xia Z K, Li B S et al., 2008. Lateral stratigraphy and stratigraphic division of southern China. Quaternary Research, 28(1): 1-13. (in Chinese)

Zhang J F, Huang W, Yuan B Y et al., 2010. Optically stimulated luminescence dating of cave deposits at the Xiaogushan prehistoric site, northeastern China. Journal of Human Evolution, 59(5): 514-524.

Zhang J F, Li Y, Han Y et al., 2019. Luminescence dating of weathered sediments from the paleolithic site of Fengshuzui in northern Hunan province, China. Quaternary Geochronology, 49: 211-217.

Zhang J F, Yuan B, Zhou L, 2007. The luminescence chronology of the "old red sand" in Jinjiang, Fujian, and its significance for the lunar dating of Quaternary sediments in the south. Science Bulletin, 52(22): 2646-2654. (in Chinese)

Zhang J J, Li S H, 2020. Review of the post-IR IRSL dating protocols of K-feldspar. Methods and Protocol, 3(1): $10.3390 / \mathrm{mps} 3010007$.

Zhang P F, Hu X F, An B N et al., 2018. Comparison of geochemical characteristics between the Basaltic red clay and Quaternary red clay in Hainan. Chinese Journal of Soil Science, 49(5): 1009-1014. (in Chinese)

Zhang S, Gao X, Xu X M, 2003. Investigation report of Paleolithic in Zhejiang Province. Journal of Anthropology, 22(2): 105-119. (in Chinese)

Zhao H, Li S, 2005. Internal dose rate to K-feldspar grains from radioactive elements other than potassium. Radiation Measurements, 40(1): 84-93.

Zhejiang Provincial Institute of Cultural Relics and Archaeology (ZPICRA), 2009. Changxing County Cultural Relics Protection and Management Office. Qiliting and Yingdinggang. Beijing: Science Press. (in Chinese)

Zhu L D, Jiang Y J, Zhang M Q et al., 2011. Magnetic susceptibility characteristics and paleoenvironment records of laterite in the Lushan JL profile. Mountain Journal, 29(4): 385-394. (in Chinese)

Zhu L D, Zhou S Z, Ye W et al., 2005. Research on laterite deposition and environmental change in southern China. Journal of Zhejiang Normal University (Natural Science Edition), 28(2): 206-210. (in Chinese) 